\title{
SPIB Acts as a Tumor Suppressor by Activating NFkB and JNK Signaling Pathways Through MAP4K1 in Colorectal Cancer Cells
}

\section{Xunping Zhao}

The First Affiliated Hospital of Chongqing Medical University

Lin Li

The First Affiliated Hospital of Chongqing Medical University

Shiyun Yuan

The First Affiliated Hospital of Chongqing Medical University

\section{Qia Zhang}

Yongchuan Hospital of Chongqing Medical University

\section{Xianyao Jiang}

The First Affiliated Hospital of Chongqing Medical University

Tao Luo ( $D$ luotao@hospital.cqmu.edu.cn )

The First Affiliated Hospital of Chongqing Medical University https://orcid.org/0000-0001-8357-6918

\section{Primary research}

Keywords: SPIB, colorectal cancer, MAP4K1, tumor suppressor

Posted Date: December 31st, 2020

DOI: https://doi.org/10.21203/rs.3.rs-136420/v1

License: @ (i) This work is licensed under a Creative Commons Attribution 4.0 International License. Read Full License 


\section{Abstract}

\section{Background}

Colorectal cancer (CRC) is one of the major cancers in the world. Spi-B Transcription Factor (SPIB) is one member of the E-twenty-six (ETS) transcription factor family. Previous studies have shown that the expression of SPIB is down-regulated in human colorectal cancer tissues. However, its biological function in colorectal cancer cells is not reported. The purpose of our study is to explore the biological function and related mechanism of SPIB in colorectal cancer cells, to provide reference for the molecular detection and targeted drug therapy of colorectal cancer.

\section{Methods}

The biological function of SPIB in colorectal cancer cells were studied by colony formation assay, CCK-8 cell proliferation assay, transwell assay, tube formation assay, flow cytometry analysis. Growth inhibition assay was used to measure the impact of SPIB on oxaliplatin and 5-fluorouracil (5-FU). Double luciferase reporter assay and western blot were used to detect mechanism of SPIB in colorectal cancer cells.

\section{Results}

SPIB mRNA was down-regulated in CRC cell lines and CRC tissues. SPIB can inhibit the proliferation, migration and invasion of CRC cells; can inhibit angiogenesis; and induce the cell cycle of CRC cells arrest in G2/M phase and promote the apoptosis of CRC cells. In the growth inhibition assay we found that compared with the control group, the $50 \%$ inhibitory concentration(IC50) values of oxaliplatin and 5-FU in the SPIB overexpression group were significantly reduced. Western blot results showed that the overexpression of SPIB upregulated cleaved-PARP(c-PARP), nuclear factor kB p65 (NFkB p65), phospho-NFkB p65(p-NFkB P65), JNK1, and C-Jun proteins expression level compared with the control group. Double luciferase report experiment showed that SPIB can activate the promoter of MAP4K1 and enhance the expression of MAP4K1. After silencing MAP4K1, the protein expressions of c-PARP, NFkB P65, p-NFkB P65, JNK1, and C-Jun were down-regulated.

\section{Conclusions}

In this study, we found that SPIB is a tumor suppressor in colorectal cancer cells, SPIB sensitizes colorectal cancer cells to oxaliplatin and 5-FU. we also found that MAP4K1 is a target gene of SPIB, SPIB exerts its anti-colorectal cancer effect by activating NFkB and JNK signaling pathways through MAP4K1. The above findings may provide reference for new molecular markers and therapeutic targets for CRC.

\section{Background}

$\mathrm{CRC}$ is one of the most common cancers in the world, with the third highest incidence and the second highest mortality among malignant tumors [1]. More and more evidence show that CRC is not a single gene disease but a disease caused by a series of genetic changes. Molecular marker detection and molecular targeted drug therapy are the focus of current research.

The ETS transcription factor family is one of the largest transcription factor families. This family has 28 genes, and its members are related to the development of different tissues and cancer. All ETS family proteins have a highly conserved DNA-binding domain, namely ETS domain, which has a flanking helix and can bind to the DNA-binding site of GGA (A/T) sequence [2]. The ETS family has a variety of functions, including regulation of cell differentiation, cell cycle, cell migration, cell proliferation, apoptosis, angiogenesis and so on[3]. Many members of the ETS family have been shown to be associated with cancer.

SPIB transcription factor protein belongs to the ETS transcription factor family. Human SPIB is located on chromosome 19q13.3-q13.4. It is mainly expressed in mature B cells, plasma cell-like cells and T cell precursor cells. Real-time polymerase chain reaction and immunohistochemical detection were performed on $28 \mathrm{CRC}$ tissues and paired non-tumor tissues by some researchers, the results showed that SPIB was mainly distributed in the nucleus and down-regulated in CRC tissues [4]. However, there is no report of the biological function and related mechanism of SPIB in CRC cells. The purpose of this study is to explore the biological function and mechanism of SPIB in human CRC cells, in order to provide reference for molecular detection and targeted drug therapy of Colorectal cancer. 


\section{Materials And Methods}

\section{Cells lines and tumour samples}

Human CRC cell lines (HCT116, CaCO2, RKO, SW480, LoVo, HT-29) and Human umbilical vein endothelial cells (HUVECs) were selected. CaCO2, RKO, LoVo and SW480 cells were purchased from the Chinese Academy of Sciences. HCT116 and HT-29 were presented by Professor Q.tao of the Chinese University of Hong Kong. HUVECs were purchased from American Type Culture Collection. The cells were cultured in RPMI-1640 medium (Gibco-BRL, Karlsruhe, Germany) containing 10\% fetal bovine serum (ExCell Bio, Shanghai, China), cultured in $5 \% \mathrm{CO} 2,37^{\circ} \mathrm{C}$ humidified atmosphere [5]. The CRC tissues and paired non-tumor tissues of 25 patients in the tumor tissue specimen database of the First Affiliated Hospital of Chongqing Medical University (Chongqing, China) were collected. All the tissues have been identified and kept at $-80^{\circ} \mathrm{C}$. The research scheme was approved under the guidance of the Ethics Committee of the First Affiliated Hospital of Chongqing Medical University.

\section{Nucleic acid and protein extraction}

Total RNA was extracted from CRC tissues and cell lines with TRIzol ${ }^{8}$ reagent (Life Technologies, Carlsbad, CA, USA). The extracted RNA was measured by NanoDrop 2000 spectrophotometer (Thermo Scientific, Rockford, IL, USA) and stored at $-80^{\circ} \mathrm{C}$. Total protein was extracted from HCT116, RKO and HT-29 cells. The cells were lysed by protein extraction reagent (Thermo Scientific) in the experimental group and the control group, then the lysate was collected into EP tubes and homogenized by ultrasonic cell grinder (Scientz, Ningbo). After centrifugation at $4^{\circ} \mathrm{C}$, the supernatant was transferred to new EP tubes. The protein concentration was measured by BCA protein kit (Thermo Scientific) $₫$ then stored in $-80^{\circ} \mathrm{C}$ refrigerator [6].

\section{Reverse Transcription Polymerase Chain Reaction (RT-PCR) and Quantitative Real-time Polymerase Chain Reaction (qRT-PCR)}

The expression of SPIB in CRC cells and tissues was detected by RT-PCR and qRT-PCR. $1 \mu \mathrm{g}$ RNA was reverse transcribed into $20 \mu \mathrm{g}$ CDNA using the reverse transcription system (Promega, Madison, WI, USA). For RT-PCR, the SPIB gene was amplified by GoTaq DNA polymerase (Promega) with 32 cycles, the internal control was $\beta$-actin. SYBR® Green PCR Master Mix (Thermo Fisher Scientific, Hong Kong, China) was used in the qRT-PCR, ABI 7500 Real-Time PCR system (Applied Biosystems, Foster City, CA, USA) was used for amplification, and $\beta$-actin as control. The primer sequences are shown in Table 1.

\section{Construction of SPIB overexpressed stable cell lines}

The pCMV6-SPIB plasmid (OriGene Technologies, Inc. USA) and pCMV6-Entry plasmid were transfected into RKO and HT-29 cells with the transfection reagent Lipofectamine ${ }^{\circledR} 2000$ (Invitrogen, Thermo Fisher Scientific, Inc.) respectively. After being cultured in serum-free RPMI-1640 medium for 4-6h, the fresh medium containing 10\% FBS was used to replace the medium. After 48h, the G418 (Invitrogen/Gibco) was added to the medium containing 10\% FBS for about 20 days to obtain the stable cell lines of SPIB overexpressed. RKO and HT-29 cells were screened at concentrations of $800 \mathrm{ug} / \mathrm{ml}$ and $1200 \mathrm{ug} / \mathrm{ml}$. RT-PCR, qRT-PCR and western blot were used to verify the results.

\section{SPIB gene was silenced in CRC cells}

HCT116 cells were plated in a 6-well plate, the next day the confluence degree of 70\% could be reached. siRNA-SPIB (Ribobio, China) was transfected into HCT116 cells with the transfection reagent Lipofectamine ${ }^{\circledR} 2000$, siRNA-NC was used as control. After being cultured in serum-free RPMI-1640 medium for 4-6h, the fresh medium containing $10 \%$ FBS was used to replace the medium. Cultured for 48 hour, the cells were collected for later experiments.

\section{Colony formation assay}

Cells of experimental group and control group were cultured in a 6-well plate $(200,400,800$ cells / well) for $10-14$ days. Fixed with $4 \%$ paraformaldehyde for 30 minutes, then stained with Gentian Violet (ICM pharma, Singapore) for 15 minutes.

\section{CCK-8 Cell proliferation assay}

Cells of experimental group and control group were planted in a 96-well plate at the density of 3000-6000/well, cultured in 100ul/well

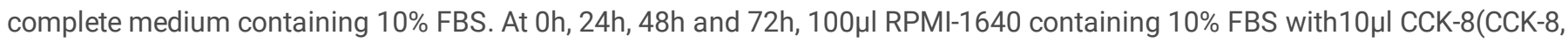
Beyotime, Shanghai, China) solution was used to replace the culture medium of each well and incubated at $37^{\circ} \mathrm{C}$ for 2 hours. The 
absorbance was measured with a microplate reader (Multiskan MK3; Thermo Fisher Scientific, former Fermentas, Schwerte, Germany) at $450 \mathrm{~nm}$, all the experiments were repeated three times.

\section{Transwell assays}

Without or with Matrigel barrier (BD Biosciences) in the top of transwell chamber ( $8 \mu \mathrm{m}$ pore size; Corning, New York, New York, USA) to detect the migration or invasion ability of CRC cells [7]. Cells were digested and centrifuged. After serum-free medium suspension, cells (RKO cells $4 \times 10^{4}$, HT-29 cells $12 \times 10^{4}$ ) were made into $200 \mu$ cell suspension区added to the upper transwell chamber, and 700 $\mu$ l RPMI1640 containing $30 \%$ FBS was added to the lower chamber. After incubating at $37^{\circ} \mathrm{C}$ and $5 \% \mathrm{CO} 2$ for $48-56 \mathrm{~h}$, the cells in the lower part of the chamber were fixed in $4 \%$ paraformaldehyde for 30 minutes, and stained in Gentian Violet for $15 \mathrm{~min}$. The cells in upper part of the chamber were wiped off with cotton buds. These cells in 5 random fields were counted under 400x magnifying microscope (CTR4000; Leica, Wetzlar, Germany). All the experiments were repeated three times.

\section{Tube formation assay}

Matrigel barrier diluted (Matrigel: RPMI-1640 $=1 \otimes 1$ ) and placed into a 96 -well plate according to $50 \mathrm{ul} /$ well. When the Matrigel barrier was solidified, the HUVECs cells were placed into the 96 -well plate at a density of $60-70 \%$ / well. The control group was added with the original culture medium of RKO cells transfected with pCMV6-Entry and the experimental group was added with the original culture medium of RKO cells transfected with pCMV6-SPIB, 100ul/well. After 8 hours of culture, images were collected using a fluorescence microscope. All the experiments were repeated three times.

\section{Flow cytometry analysis of cell cycle and apoptosis}

In the determination of cell cycle, stably overexpressing cells were collected, after digesting, centrifuge with 1000rpm for 5 minutes, then with $4 \mathrm{ml}$ PBS re-suspension, centrifugation for 5 minutes again, fixed it with ice-cold $70 \%$ ethanol for 5 days at $-20^{\circ} \mathrm{C}$. The fixed cells were stained with $50 \mathrm{mg} / \mathrm{l}$ propidium iodide $(\mathrm{PI})$ to avoid light for $37^{\circ} \mathrm{C}, 30 \mathrm{~min}$. In the determination of apoptosis, the original culture medium was collected. After digesting, centrifugating, resuspending and centrifugating $₫$ Annexin V-FITC (BD Pharmingen, San, Jose, CA USA) and PI were used to stain in the dark for 20 minutes, then analyzed by flow cytometry (BD Bioscience, Franklin Lakes, New Jersey, USA). The results were analyzed by Cell Quest software (BD Biosciences, San Jose, California, USA). All the experiments were repeated three times.

\section{Western blot assay}

The 40ug protein was used for western blot as previously mentioned [8]. The main antibodies to be used were as follows: GAPDH (1:1000) (2118, Cell Signaling Technology), Bax (1:1000) (5023, Cell Signaling Technology), SPIB (1:1000) (15768-1-AP, Proteintech), PARP/cleaved-PARP (1:750) (WL01932,Wanleibio), MAP4K1(1:1000) (23950-1-AP囚Proteintech), NFkB p65 (1:500) (WL01980囚 Wanleibio), P-NFkB p65 (1:1000) (WL02169,Wanleibio), JNK1(1:1000) (TA500043,Origene), C-Jun (1:1000) (TA500226,Origene). The enhanced chemiluminescence detection system (PierceChemical Co, Rockford, IL) was used for Proteins imaging.

\section{Growth inhibition assay}

Cells were inoculated into 96-well plates, 8000/well. 6h later, the cells were exposed to oxaliplatin (EAIE000ZA, QILU) with increased concentration gradient $(0,0.5,1,2,4,8 \mathrm{ug} / \mathrm{ml})$ or $5-\mathrm{FU}(0,0.01,0.1,1,10 \mathrm{ug} / \mathrm{ml})$. After 48 hours of incubation, $100 \mu \mathrm{l}$ RPMl-1640 containing $10 \%$ FBS with $10 \mu \mathrm{l} \mathrm{CCK}-8$ solution was used to replace the culture medium of each well, incubated at $37^{\circ} \mathrm{C}$ for 2 hours. The absorbance was measured with a microplate reader at $450 \mathrm{~nm}$, and the $\mathrm{IC}_{50}$ value was calculated by Prism statistical software (GraphPad Software, San Diego, CA). All the experiments were repeated 3 times.

\section{Identification of SPIB associated target genes}

In order to further analyze the molecular mechanism of SPIB, we downloaded RNA-sequencing data from TCGA database, and the samples were divided into SPIB high expression group (237 CRC patients) and SPIB low expression group (236 CRC patients) by median expression value of SPIB gene. The top $50 \mathrm{p}$-value $<0.05$ signaling pathways were obtained through gene set enrichment analysis. The signal pathways with great correlation with CRC were found by literature review. Through the analysis of the signal pathways, the target gene that may be related to SPIB was found.

\section{Double luciferase reporter assay}


In order to explore the interaction of transcription factor SPIB and the MAP4K1 promoter region, 293T cells were inoculated into a 24well plate, the cell density increased to $60 \%-70 \%$ per well on the second day. Four groups were set up and transfected with pHGPromDetect-NC+pCMV6-Entry, pHG-PromDetect-NC+pCMV6-SPIB, pHG-PromDetect-MAP4K1p+pCMV6-Entry and pHG-PromDetect-

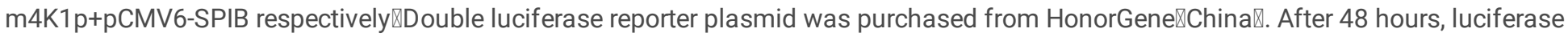
activity was detected by double luciferase reporter kit (PROMEGA) and expressed as relative activity. All the experiments were repeated three times.

\section{Statistical analysis}

For all analyses, a double-tailed t-test from the GraphPad software was used to assess the difference between the cell control group and the experimental group. P-values $<0.05$ was considered to be statistically significant.

\section{Results}

\section{SPIB mRNA is down-regulated in CRC cell lines and CRC tissues}

The online database UALCAN (http://ualcan.path.uab.edu/analysis.html) showed that the expression of SPIB mRNA in Rectum adenocarcinoma (READ) and Colon adenocarcinoma (COAD) tissues was lower than that in normal colorectal tissues(Fig. 1a). We used RT-PCR to detect the expression of SPIB mRNA in colorectal cancer cell lines (HCT116, HT-29, LoVo, SW480, CaCO2 and RKO), the colorectal non-tumor tissues were used as control. The result showed that the expression of SPIB mRNA was significantly downregulated in 6 CRC cell lines (Fig. 1b). We used qRT-PCR to detect the expression of SPIB mRNA in 25 CRC tissues and paired non-tumor tissues. The results showed that the expression level of SPIB mRNA in $88 \%(22 / 25)$ CRC tissues was significantly lower than that in the paired non-tumor tissues (Fig. 1C) $(P<0.05)$. The clinical information of CRC patients is shown in Table 2.

\section{mRNA and protein levels were verified after the SPIB gene was overexpressed and silenced in CRC cells}

As the expression of SPIB mRNA in HT-29 and RKO cells was significantly reduced, the overexpressed plasmid pCMV6-SPIB was transfected to construct SPIB overexpressed stable strain, and transfection of plasmid pCMV6 - Entry as control. Since the expression of SPIB mRNA in HCT116 cells was higher than that in the other 5 CRC cell lines, SPIB in HCT116 cells was silenced by transfection siRNASPIB, and siRNA-NC was used as the control. Total mRNA and protein of the experimental group and the control group were extracted respectively. RT-PCR, qRT-PCR and western blot were used for detection. The results showed that the mRNA and protein levels of SPIB in HT-29 and RKO cells were significantly higher than those in the control group, and the mRNA and protein levels of SPIB in HCT116 cells were significantly lower than those in the control group (Fig. 2a, 2b and 2c). These results suggested that SPIB overexpressed stable cell lines and SPIB silenced cell lines were successfully constructed.

\section{SPIB inhibits the proliferation of CRC cells}

Colony formation assay showed that compared with the control group, the number of clones of HT-29 and RKO cells after SPIB overexpression was significantly reduced $(\mathrm{P}<0.001)$ (Fig. $2 \mathrm{~d}$ and $2 \mathrm{e}$ ). The results of CCK-8 cell proliferation assay showed that compared with the control group, HT-29 and RKO cell lines with stable overexpression of SPIB decreased significantly in cell proliferation at 24h, 48h and $72 \mathrm{~h}(\mathrm{P}<0.01)$ (Fig. $2 \mathrm{f}$ and $2 \mathrm{~g})$. The proliferation of HCT116 cells of SPIB silenced was significantly increased at $24 \mathrm{~h}, 48 \mathrm{~h}$ and $72 \mathrm{~h}(\mathrm{P}<0.05)$ (Fig. $2 \mathrm{~h})$. These results suggested that SPIB could inhibit the proliferation of CRC cells.

\section{SPIB inhibits migration and invasion of CRC cells}

Transwell assay was used to detect the effect of SPIB on the migration and invasion ability of CRC cells. For migration, the number of cells passing through the chamber membrane is shown below: HT-29 cells in the SPIB overexpression group (22 \pm 2.646$)$ were significantly less than those in the control group $(94.67 \pm 19.40)$,RKO cells in the SPIB overexpression group (13 \pm 5.92$)$ were significantly

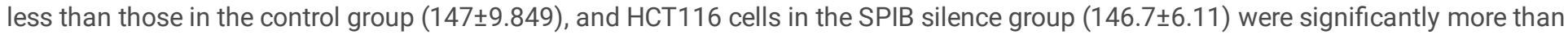
those in the control group (70.67 \pm 2.517$)$ (Fig.3a囚3b and $3 c$ ). With statistically significant differences $(P<0.01)$. These results suggested that SPIB can reduce the migration ability of CRC cells. For invasion, the number of cells passing through the chamber membrane is

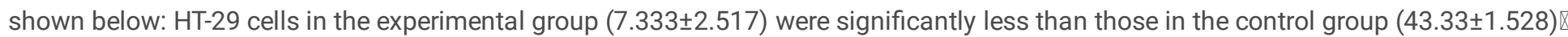
RKO cells in the experimental group (18 \pm 4$)$ were significantly less than those in the control group (194 \pm 19.08$)$, and HCT116 cells in the

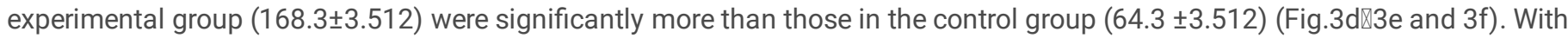
statistically significant differences $(P<0.01)$. These results suggested that SPIB can reduce the invasion ability of $C R C$ cells. 


\section{SPIB inhibits angiogenesis}

In the tube formation assay, we found that the number of tubules formed in the SPIB overexpression group was significantly lower than that of the control group (Fig.3g). It suggested that SPIB can inhibit angiogenesis.

\section{SPIB can induce the cell cycle of CRC cells arrest in G2/M phase and promote the apoptosis of CRC cells}

Flow cytometry was used to detect the effect of SPIB on the cell cycle and apoptosis of CRC cells. When the cell cycle was detected, we found that in RKO(Fig.4a 44 b) and HT-29(Fig.4c $\varangle 4$ d) cells, the number of cells in the G2/M phase was significantly higher in the SPIB overexpression group than in the control group $(P<0.05)$. The results suggested that SPIB could induce the cell cycle of CRC cells arrest in G2/M phase. In the detection of cell apoptosis, the results showed that the apoptosis percentage of HT-29 and RKO cells in SPIB overexpression group was significantly higher than that in the control group $(P<0.001)$ (Fig. $4 \mathrm{e}$ and $4 \mathrm{f})$. The results suggested that SPIB could promote the apoptosis of CRC cells.

\section{SPIB up-regulates c-PARP protein expression and activates NFkB and JNK signaling pathways}

Western blot was used to detect the protein expression level associated with apoptosis, we found that in HT-29 and RKO cells, overexpression of SPIB up-regulated NFkB P65, p-NFkB P65, c-PARP, JNK1, and C-Jun proteins expression level compared with the control group (Fig. 4g).

\section{SPIB sensitizes colorectal cancer cells to oxaliplatin and 5-FU}

The effects of SPIB on oxaliplatin and 5-FU against CRC were investigated by growth inhibition assay. The IC50 value of oxaliplatin was as follows: $I C_{50}$ pCMv6-Entry $=1.83, I C_{50}$ pCMV6-SPIB $=0.5964$. (Fig.5a). The IC50 value of the control group was 3.068 times higher than that of the SPIB overexpression group. The IC50 value of 5-FU was as follows: IC 50 pCMV6-Entry $=1.214, I_{50}$ pCMV6-SPIB $=0.1033$. (Fig.5b). the IC50 value of the control group was 11.75 times higher than that of the SPIB overexpression group. These results suggest that SPIB can up-regulate the sensitivity of colorectal cancer cells to oxaliplatin and 5-FU.

\section{SPIB can activate the promoter of MAP4K1 and enhance the expression of MAP4K1}

In order to further study the mechanism of SPIB in CRC, we obtained SPIB-related signaling pathways in CRC through gene set enrichment analysis, including MAPK, JAK-STAT and APOPTOSIS signaling pathways (Fig.6a).In the MAPK pathway, we found that the expression level of SPIB in CRC tissues affected the expression level of MAP4K1 (Fig.6b).In GEPIA database (http://gepia.cancerpku.cn/detail.php), the expression of SPIB was positively correlated with MAP4K1 (Fig. 6c).By using qRT-PCR and western blot to detect the correlation between the mRNA and protein levels of SPIB and MAP4K1, we found that the expression of MAP4K1 up-regulated after SPIB was overexpressed and decreased after SPIB was silenced $(P<0.05)$ (Fig. 6d and 6e). In order to further explore the interaction between SPIB and the promoter region of MAP4K1, we conducted double luciferase reporter assay, the results showed that SPIB overexpression could enhance the luciferase activity of MAP4K1 compared with the control group $(P<0.01)($ Fig. 6f). The results suggested that SPIB can activate the promoter of MAP4K1 and enhance the expression of MAP4K1.

\section{SPIB up-regulates c-PARP protein expression and activates NFkB and JNK signaling pathways by upregulation of MAP4K1}

In order to explore whether MAP4K1 is the target gene of SPIB, RKO cells with SPIB overexpression were transfected with siRNA-MAP4K1 and siRNA-NC (Ribobio, China) respectively, confirmed by qRT-PCR( $\mathrm{P}<0.001)$ (Fig. 7a) and western blot(Fig. 7b).The results suggested that the MAP4K1 gene was successfully silenced in the RKO cells that stably overexpressing of SPIB. Subsequently, western blot was used to detect the protein expression level of the above associated with apoptosis after silencing MAP4K1, and the results showed that the protein expressions of c-PARP, NFkB P65, p-NFkB P65, JNK1, and C-Jun were down-regulated (Fig.7c). The above results indicated that MAP4K1 is the target gene of SPIB, and SPIB activates NFkB and JNK signaling pathways by upregulation of MAP4K1 (Fig.7d).

\section{Discussion}

SPIB is one member of the ETS transcription factor family, which is abnormally activated at all stages of oncogenesis [3].Previous studies have found that SPIB plays an important role in the occurrence and development of tumors. In acute lymphoblastic leukemia of children B lymphocyte line, the high expression of SPIB can inhibit cell proliferation and induce cell apoptosis [9].SPIB is an important transcriptional regulator of B-cell differentiation and a new tumor suppressor in the B-cell lineage [10].However, SPIB also plays a pro- 
cancer role in some tumors. For example, SPIB can promote the invasion of lung cancer cells [11]. SPIB is anti-apoptotic through PI3KAKT pathway in diffuse large B-cell lymphoma [12]. The expression of SPIB may be related to the poor prognosis of liver cancer and may be used as a clinical prognostic indicator of liver cancer[13]. Previous Study has shown that the expression level of SPIB in CRC tissues is lower than that in paired non-tumor tissues [4]. In our study, we also found that the expression of SPIB in CRC tissues and cell lines were silenced or down-regulated, suggesting that SPIB may play a role of cancer inhibition in CRC. However, the biological function and mechanism of SPIB in CRC have not been reported so far, so we conducted further research on it.

The effect of SPIB on the growth and metastasis of CRC cells was studied by CCK-8 cell proliferation assay, clone formation assay, flow cytometry, transwell assay and other in vitro assays. This study found that SPIB overexpression inhibited the proliferation, migration and invasion of CRC cells, promoted the apoptosis of CRC cells and induced cell cycle arrest in G2/M phase. It has been reported that ETS family members have the ability to regulate angiogenesis[14]. In our study, tube formation assay has shown that SPIB can inhibit angiogenesis. All the above results indicate that SPIB may be a tumor suppressor gene in CRC. To further confirm this conclusion, SPIB was silenced in CRC cells, and the results showed that the ability of CRC cells to proliferate, migrate and invade was significantly enhanced after SPIB silencing, which further confirmed the anticancer effect of SPIB in CRC cells.

Oxaliplatin is the third generation of platinum anticancer drugs, is the most commonly used chemotherapy drugs of $\nabla$, $\nabla$ stage of colorectal cancer patients after surgical resection[15]. Through the growth inhibition assay, we found that the IC50 value of the control group was 3.068 times higher than that of the SPIB overexpression group, indicating that the high expression of SPIB could increase the sensitivity of CRC cells to oxaliplatin. Since the activation of JNK can promote oxaliplatin induced apoptosis [16], we believe that the high expression of SPIB induces the sensitivity of CRC cells to oxaliplatin by activating the JNK pathway. 5-FU is a commonly used chemotherapy drug in tumor therapy [17], which mainly targets at the $S$ phase of cell cycle and other phases to play an anti-tumor role[18]. In this study, the growth inhibition assay found that the IC50 value of the control group was 11.75 times higher than that of the SPIB overexpression group, suggesting that SPIB could increase the sensitivity of CRC cells to 5-FU. We believed that the high expression of SPIB could induce the cycle arrest of CRC cells in the G2/M phase, leading to increase sensitivity to 5-FU. Since clinical chemotherapy failure is often caused by the resistance of tumor cells to chemotherapy drugs, our study provides a new probability for the treatment of CRC patients.

In order to explore how SPIB acts on colorectal cancer, we conducted corresponding studies.

1. PARP is considered to be an important protein involved in DNA repair[19]. Proteolysis of PARP is considered to be an early molecular marker of programmed cell death, PARP cleavage during apoptosis promotes cell disintegration [20].c-PARP is the product of PARP cleavage. In our study, c-PARP expression was up-regulated after SPIB overexpression. Therefore, we believe that the overexpression of SPIB induced apoptosis of colorectal cancer cells.

2. NFkB is a family of transcription factors that play an important role in tumor proliferation, migration and apoptosis [21].Activated NFkB has been reported to promote the apoptosis of ovarian cancer cells [22].NFkB p65 is the core of NFkB signaling pathway, and the level of p-NFkB P65 can reflect the activation degree of NFkB signaling pathway [23]. When exposed to specific stimuli, NFkB signaling pathways are activated and free p-NFkB P65 is introduced into the nucleus and combined with corresponding DNA sequences to induce transcription of target genes [23], thus affecting tumor growth and metastasis. In this study, the expressions of NFkBp65 and p-NFkBP65 were up-regulated after SPIB overexpression. Therefore, we believe that SPIB may also induce the apoptosis of CRC cells by activating NFkB signaling pathway.

3. JNK is a key protein in the downstream of the three-level activation system of MAPK protein kinase. JNK plays an important role in biological processes such as cell proliferation, differentiation and apoptosis[24].The transcription factor C-Jun is a downstream target of JNK and can regulate the expression of pro-apoptotic or anti-apoptotic genes [25].Studies have shown that the activation of the JNK/C-Jun pathway can lead to the apoptosis of CRC cells[26].Our data showed that the overexpression of SPIB upregulated both JNK1 and C-Jun proteins. Therefore, we believe that SPIB may induce the apoptosis of CRC cells by activating the JNK/C-Jun pathway.

In order to further study the mechanism of SPIB in CRC, we found that MAP4K1 may be the target of SPIB through gene set enrichment analysis. MAP4K1, known as human hematopoietic progenitor cell kinase 1, is a member of the MAP4K family of kinases [27].It has been reported that MAP4K family kinases can activate the upstream molecules of MAP3Ks and MAP2Ks, thus activating the MAPK/JNK signaling pathway[28-31], and MAP4K1 proteins can be activated during apoptosis[32].By western blot, qRT-PCR and double luciferase reporter assay, we found that SPIB can enhance the expression of MAP4K1. We also found that the protein expressions of c-PARP, NFkB P65, p-NFkB P65, JNK1 and C-Jun were down-regulated in the SPIB overexpressed stable strain after MAP4K1 silence. Therefore, we

Page $7 / 18$ 
believe that MAP4K1 is a target gene of SPIB, and SPIB may induce the apoptosis of CRC cells by activating NFkB and JNK signaling pathways through MAP4K1.

However, the number of clinical specimens used in this study was insufficient to determine the possible relationship between SPIB and the pathological features and survival prognosis of colorectal cancer. In future, we will collect more clinically matched samples to

further study the relationship between SPIB and clinicopathology and prognosis, so as to provide reference for molecular detection and targeted drug therapy of Colorectal cancer.

\section{Conclusion}

In summary, this study found that SPIB acts as a tumor suppressor by activating NFkB and JNK signaling pathways through MAP4K1, and increases the sensitivity of CRC cells to oxaliplatin and 5-FU. SPIB may provide reference for new molecular markers and therapeutic targets for CRC.

\section{Abbreviations}

CRC Colorectal cancer

ETS E-twenty six

5-FU 5-fluorouracil

c-PARP cleaved-PARP

NFkB p65 Nuclear factor kB p65

p-NFkB P65 Phospho-NFkB p65

RT-PCR Reverse Transcription Polymerase Chain Reaction

qRT-PCR Quantitative Real-time Polymerase Chain Reaction

READ Rectum adenocarcinoma

COAD Colon adenocarcinoma

$\mathrm{IC}_{50} 50 \%$ inhibitory concentration

\section{Declarations}

\section{Ethics approval and consent to participate}

This work was approved by the Ethics Committee of the First Affiliated Hospital of Chongqing Medical University, the Approval Number is 2020 Research Ethics $₫ 2020-340 \rrbracket$.

\section{Consent for publication}

Not applicable.

\section{Availability of data and materials}

The datasets used and/or analyzed during the current study are available from the corresponding author on reasonable request.

\section{Competing interests}

The authors declare that they have no competing interests.

Funding 
This study was funded by Tao Luo's personal funds (202257GRJFJY).

Authors' contributions

XPZ designed the technical route of this study; XPZ, LL, SYY, XYJ were responsible for data acquisition and data analysis; XPZ was involved in data statistics; XPZ, QZ were responsible for paper writing and revision; TL was responsible for the project design and the supervision and management of the whole experiment process. All the authors approved the final manuscript.

\section{Acknowledgements}

We would like to thank Professor Tingxiu Xiang for technical assistance, and help with experimental design. We also would like to thank all those who contributed to this study.

\section{References}

1. Bray F, Ferlay J, Soerjomataram I, Siegel RL, Torre LA, Jemal A: Global cancer statistics 2018: GLOBOCAN estimates of incidence and mortality worldwide for 36 cancers in 185 countries. CA Cancer J Clin 2018, 68(6):394-424.

2. Hsing M, Wang Y, Rennie PS, Cox ME, Cherkasov A: ETS transcription factors as emerging drug targets in cancer. Med Res Rev 2020, 40(1):413-430.

3. Sizemore GM, Pitarresi JR, Balakrishnan S, Ostrowski MC: The ETS family of oncogenic transcription factors in solid tumours. Nat Rev Cancer 2017, 17(6):337-351.

4. Deves C, Renck D, Garicochea B, da Silva VD, Giulianni Lopes T, Fillman H, Fillman L, Lunardini S, Basso LA, Santos DS et al: Analysis of select members of the E26 (ETS) transcription factors family in colorectal cancer. Virchows Arch 2011, 458(4):421-430.

5. Wang C, Yue Y, Shao B, Qiu Z, Mu J, Tang J, Han X, Xiang T, Ren G: Dickkopf-Related Protein 2 is Epigenetically Inactivated and Suppresses Colorectal Cancer Growth and Tumor Metastasis by Antagonizing Wnt/ $\beta$-Catenin Signaling. Cell Physio/ Biochem 2017, 41(5):1709-1724.

6. Xiang S, Xiang T, Xiao Q, Li Y, Shao B, Luo T: Zinc-finger protein 545 is inactivated due to promoter methylation and functions as a tumor suppressor through the Wnt/ $\beta$-catenin, PI3K/AKT and MAPK/ERK signaling pathways in colorectal cancer. Int $J$ Oncol 2017 , 51(3):801-811.

7. Zhao L, Li S, Gan L, Li C, Qiu Z, Feng Y, Li J, Li L, Li C, Peng W et al: Paired box 5 is a frequently methylated lung cancer tumour suppressor gene interfering $\beta$-catenin signalling and GADD45G expression. J Cell Mol Med 2016, 20(5):842-854.

8. Li L, Tao Q, Jin H, van Hasselt A, Poon FF, Wang X, Zeng MS, Jia WH, Zeng YX, Chan AT et al: The tumor suppressor UCHL1 forms a complex with p53/MDM2/ARF to promote p53 signaling and is frequently silenced in nasopharyngeal carcinoma. Clin Cancer Res 2010, 16(11):2949-2958.

9. Xu LS, Francis A, Turkistany S, Shukla D, Wong A, Batista CR, DeKoter RP: ETV6-RUNX1 interacts with a region in SPIB intron 1 to regulate gene expression in pre-B-cell acute lymphoblastic leukemia. Exp Hematol 2019, 73:50-63.e52.

10. Sokalski KM, Li SK, Welch I, Cadieux-Pitre HA, Gruca MR, DeKoter RP: Deletion of genes encoding PU.1 and Spi-B in B cells impairs differentiation and induces pre-B cell acute lymphoblastic leukemia. Blood 2011, 118(10):2801-2808.

11. Du W, Xu X, Niu Q, Zhang X, Wei Y, Wang Z, Zhang W, Yan J, Ru Y, Fu Z et al: Spi-B-Mediated Silencing of Claudin-2 Promotes Early Dissemination of Lung Cancer Cells from Primary Tumors. Cancer Res 2017, 77(18):4809-4822.

12. Takagi Y, Shimada K, Shimada S, Sakamoto A, Naoe T, Nakamura S, Hayakawa F, Tomita A, Kiyoi H: SPIB is a novel prognostic factor in diffuse large B-cell lymphoma that mediates apoptosis via the PI3K-AKT pathway. Cancer Sci 2016, 107(9):1270-1280.

13. Ho YJ, Lin YM, Huang YC, Yeh KT, Lin LI, Lu JW: Tissue microarray-based study of hepatocellular carcinoma validating SPIB as potential clinical prognostic marker. Acta Histochem 2016, 118(1):38-45.

14. Oikawa T, Yamada T: Molecular biology of the Ets family of transcription factors. Gene 2003, 303:11-34.

15. Yang AD, Fan F, Camp ER, van Buren G, Liu W, Somcio R, Gray MJ, Cheng H, Hoff PM, Ellis LM: Chronic oxaliplatin resistance induces epithelial-to-mesenchymal transition in colorectal cancer cell lines. Clin Cancer Res 2006, 12(14 Pt 1):4147-4153.

16. Liu H, Cheng XH: MiR-29b reverses oxaliplatin-resistance in colorectal cancer by targeting SIRT1. Oncotarget 2018, 9(15):1230412315.

17. Longley DB, Harkin DP, Johnston PG: 5-fluorouracil: mechanisms of action and clinical strategies. Nat Rev Cancer 2003, 3(5):330338. 
18. Takeda H, Haisa M, Naomoto Y, Kawashima R, Satomoto K, Yamatuji T, Tanaka N: Effect of 5-fluorouracil on cell cycle regulatory proteins in human colon cancer cell line. Jpn J Cancer Res 1999, 90(6):677-684.

19. Satoh MS, Lindahl T: Role of poly(ADP-ribose) formation in DNA repair. Nature 1992, 356(6367):356-358.

20. Oliver FJ, de la Rubia G, Rolli V, Ruiz-Ruiz MC, de Murcia G, Murcia JM: Importance of poly(ADP-ribose) polymerase and its cleavage in apoptosis. Lesson from an uncleavable mutant. J Biol Chem 1998, 273(50):33533-33539.

21. Dolcet X, Llobet D, Pallares J, Matias-Guiu X: NF-kB in development and progression of human cancer. Virchows Arch 2005, 446(5):475-482.

22. Wu W, Ma B, Ye H, Wang T, Wang X, Yang J, Wei Y, Zhu J, Chen L: Millepachine, a potential topoisomerase II inhibitor induces apoptosis via activation of NF-KB pathway in ovarian cancer. Oncotarget 2016, 7(32):52281-52293.

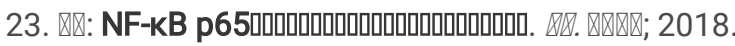

24. Cargnello M, Roux PP: Activation and function of the MAPKs and their substrates, the MAPK-activated protein kinases. Microbiol Mol Biol Rev 2011, 75(1):50-83.

25. Zhou YY, Li Y, Jiang WQ, Zhou LF: MAPK/JNK signalling: a potential autophagy regulation pathway. Biosci Rep 2015, 35(3).

26. Wang Y, Xie G, Li M, Du J, Wang M: COPB2 gene silencing inhibits colorectal cancer cell proliferation and induces apoptosis via the JNK/c-Jun signaling pathway. PLoS One 2020, 15(11):e0240106.

27. Anafi M, Kiefer F, Gish GD, Mbamalu G, Iscove NN, Pawson T: SH2/SH3 adaptor proteins can link tyrosine kinases to a Ste20-related protein kinase, HPK1. J Biol Chem 1997, 272(44):27804-27811.

28. Chuang HC, Wang X, Tan TH: MAP4K Family Kinases in Immunity and Inflammation. Adv Immunol 2016, 129:277-314.

29. Chen YR, Tan TH: The C-Jun N-terminal kinase pathway and apoptotic signaling (review). Int J Oncol 2000, 16(4):651-662.

30. Chen YR, Meyer CF, Tan TH: Persistent activation of c-Jun N-terminal kinase 1 (JNK1) in gamma radiation-induced apoptosis. J Biol Chem 1996, 271(2):631-634.

31. Chen YR, Wang X, Templeton D, Davis RJ, Tan TH: The role of C-Jun N-terminal kinase (JNK) in apoptosis induced by ultraviolet C and gamma radiation. Duration of JNK activation may determine cell death and proliferation. J Biol Chem 1996, 271(50):3192931936.

32. Chen YR, Meyer CF, Ahmed B, Yao Z, Tan TH: Caspase-mediated cleavage and functional changes of hematopoietic progenitor kinase 1 (HPK1). Oncogene 1999, 18(51):7370-7377.

\section{Tables}

Table 1

The primers used in this study

\begin{tabular}{|llllll|}
\hline PCR & Primer & Sequences $\left(5^{\prime}-3^{\prime}\right)$ & Product size(bp) & Annealing temperature $\left({ }^{\circ} \mathrm{C}\right)$ & Cycles \\
\hline RT-PCR & SPIB-F & GGAAGACTTACCGTTGGACAG & $115 \mathrm{bp}$ & 55 & 32 \\
& SPIB-R & CAGCTTCTTGCGAGTCCCT & & & 32 \\
& MAP4K1-F & AACGGAAAGAGACCAGAGCA & $205 \mathrm{bp}$ & 55 & \\
\hline & MAP4K1-R & ATGGGCTGGTACCACTGAAG & & & \\
\hline
\end{tabular}


Table 2

The clinical information of colorectal cancer tissues

\begin{tabular}{|c|c|c|c|c|c|c|c|c|c|c|c|}
\hline NO. & Age & $\begin{array}{l}\text { Gender } \\
(1 \mathrm{M} 2 \mathrm{~F})\end{array}$ & $\begin{array}{l}\text { Size } \\
(\mathrm{cm})\end{array}$ & $\begin{array}{l}\text { Grade } \\
(1234 x)\end{array}$ & $\begin{array}{l}\text { Lymph } \\
\text { metastasis }\end{array}$ & $\begin{array}{l}\text { Distant } \\
\text { Metastasis }\end{array}$ & Localization & $\begin{array}{l}\mathrm{T}- \\
\text { stage }\end{array}$ & $\begin{array}{l}\mathrm{N}- \\
\text { status }\end{array}$ & Stage & $\begin{array}{l}\text { Pathological } \\
\text { type }\end{array}$ \\
\hline 1 & 63 & 2 & $2.5,3$ & $1-2$ & 12 & 0 & Down & 2 & $2 b$ & $\triangle \mathrm{B}$ & $\mathrm{Ad}$ \\
\hline 2 & 82 & 1 & - & 2 & 0 & 0 & Right & 3 & 0 & प & $\mathrm{Ad}$ \\
\hline 3 & 63 & 2 & - & 2 & 0 & 0 & Down & 2 & 0 & प & $\mathrm{Ad}$ \\
\hline 4 & 72 & 2 & - & 1 & 11 & 0 & Left & 4 & 2 & प & $\mathrm{Ad}$ \\
\hline 5 & 66 & 1 & 3 & $1-2$ & 0 & 0 & Right & 2 & 0 & प & $\mathrm{Ad}$ \\
\hline 6 & 60 & 1 & $4 \bigotimes 7$ & - & 1 & 0 & Right & $4 a$ & $1 a$ & $\triangle \mathrm{B}$ & $\mathrm{Ad}$ \\
\hline 7 & 63 & 1 & 8 & - & 1 & 0 & Down & $4 b$ & $1 \mathrm{a}$ & $\triangle C$ & $\mathrm{Ad}$ \\
\hline 8 & 64 & 1 & $1,2.5$ & 2 & 0 & 0 & Down & $4 b$ & 0 & $\triangle C$ & $\mathrm{Ad}$ \\
\hline 9 & 52 & 2 & - & 2 & 2 & 0 & Down & 4 & 1 & $\triangle \mathrm{B}$ & $\mathrm{Ad}$ \\
\hline 10 & 93 & 2 & - & 2 & 1 & 0 & Down & 4 & 1 & $\triangle \mathrm{B}$ & $\mathrm{Ad}$ \\
\hline 11 & 55 & 1 & - & 2 & 0 & 0 & Down & 2 & 0 & प & $\mathrm{Ad}$ \\
\hline 12 & 47 & 1 & 3 & 2 & 0 & 0 & Left & $4 a$ & 0 & $\triangle \mathrm{B}$ & $\mathrm{Ad}$ \\
\hline 13 & 46 & 2 & - & $1-2$ & 9 & 0 & Down & $4 b$ & $2 b$ & $\triangle C$ & $\mathrm{Ad}$ \\
\hline 14 & 52 & 2 & - & 2 & 0 & 0 & Down & $4 a$ & 0 & $\triangle \mathrm{B}$ & $\mathrm{Ad}$ \\
\hline 15 & 62 & 2 & - & 2 & 0 & 0 & Right & $4 a$ & 0 & $\triangle \mathrm{B}$ & $\mathrm{Ad}$ \\
\hline 16 & 75 & 1 & - & 2 & 0 & 0 & Right & $4 a$ & 0 & $\triangle \mathrm{B}$ & $\mathrm{Ad}$ \\
\hline 17 & 52 & 2 & - & 2 & 0 & 0 & Down & 4 & 0 & $\triangle \mathrm{B}$ & $\mathrm{Ad}$ \\
\hline 18 & 77 & 2 & - & 2 & 1 & 0 & Left & $4 a$ & 1 & $\triangle \mathrm{B}$ & $\mathrm{Ad}$ \\
\hline 19 & 68 & 1 & - & $1-2$ & 0 & 0 & Left & 1 & 0 & प & $\mathrm{Ad}$ \\
\hline 20 & 46 & 1 & - & 2 & 0 & 0 & Left & $4 a$ & 0 & प & $\mathrm{Ad}$ \\
\hline 21 & 74 & 2 & 5,5 & 2 & 0 & 0 & Left & 4 & 0 & $\triangle \mathrm{B}$ & $\mathrm{Ad}$ \\
\hline 22 & 72 & 1 & - & 2 & 1 & 0 & Down & $4 a$ & $1 a$ & $\triangle A$ & $\mathrm{Ad}$ \\
\hline 23 & 75 & 2 & - & 2 & 0 & 0 & Right & $4 a$ & 0 & $\triangle \mathrm{B}$ & $\mathrm{Ad}$ \\
\hline 24 & 64 & 2 & - & 1 & 0 & 0 & Right & $4 a$ & 0 & $\triangle \mathrm{B}$ & $\mathrm{Ad}$ \\
\hline 25 & 76 & 2 & - & 2 & 0 & 0 & Left & $4 a$ & 0 & $\nabla \mathrm{B}$ & $\mathrm{Ad}$ \\
\hline
\end{tabular}

\section{Figures}




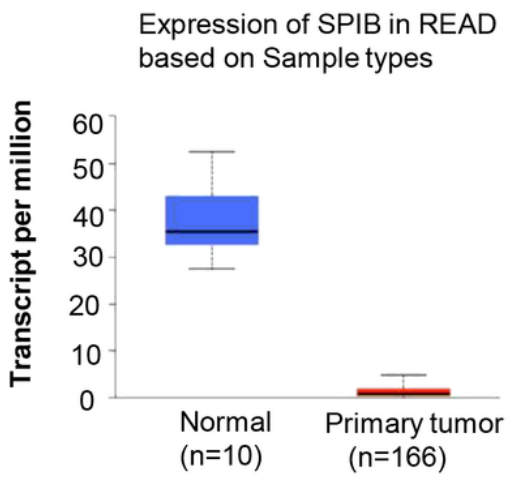

TCGA samples

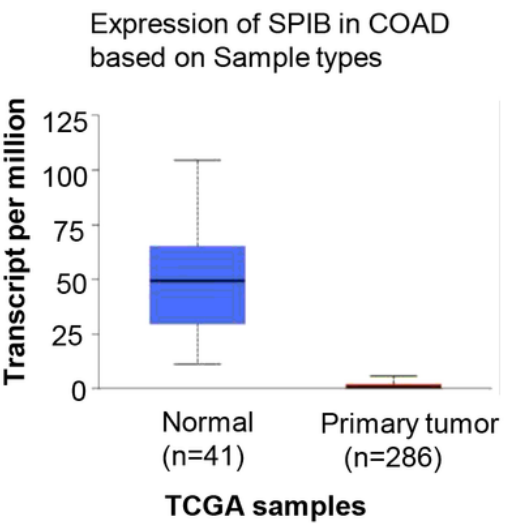

TCGA samples

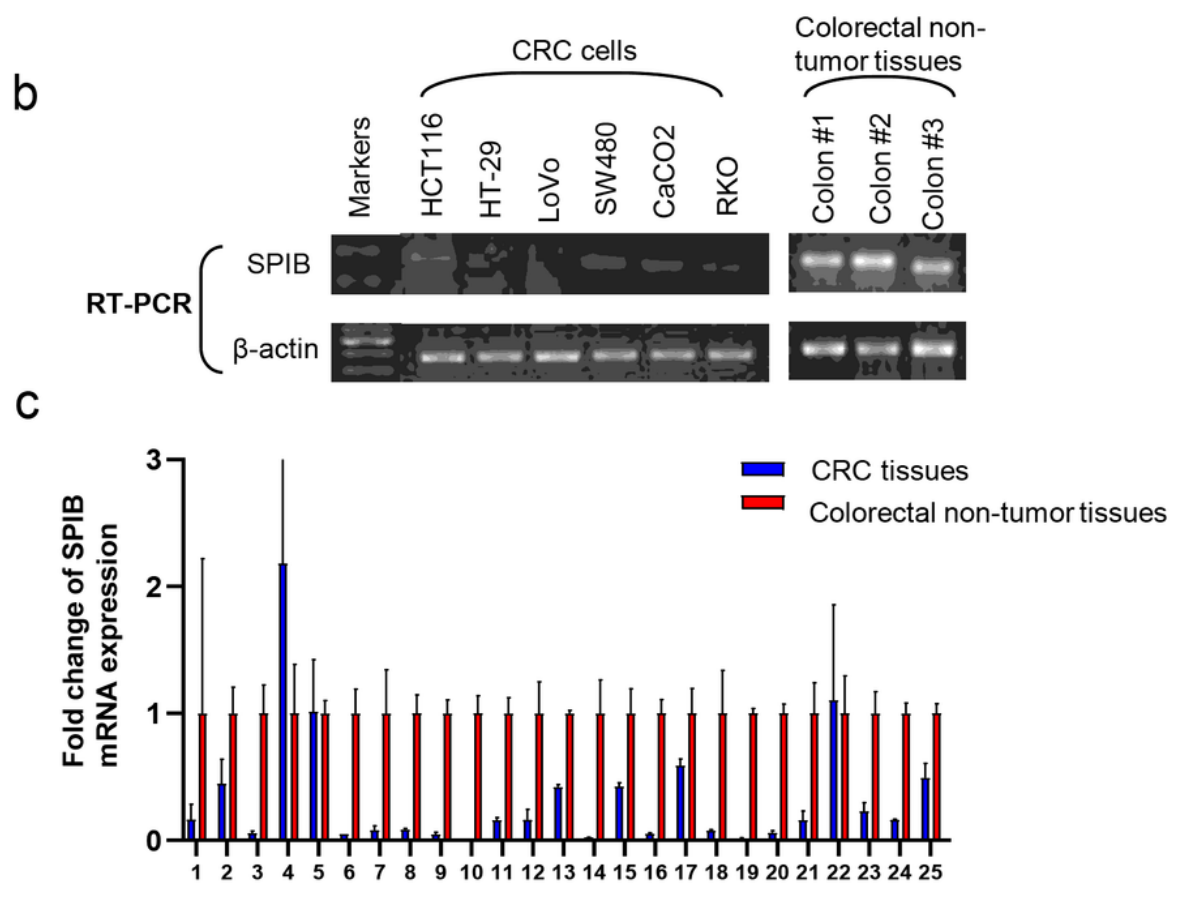

Figure 1

The expression of SPIB mRNA in CRC cell lines and tissues. (a)The expression of SPIB mRNA in Rectum Adenocarcinoma (READ) and Colon Adenocarcinoma (COAD) on UALCAN website. (http://ualcan.path.uab.edu/analysis.html). (b)The expression of SPIB mRNA in CRC cell lines and colorectal non-tumor tissues. (c)QRT-PCR was used to detect the expression of SPIB mRNA in 25 pairs of CRC and colorectal non-tumor tissues. Abbreviations: CRC, colorectal cancer. 
a

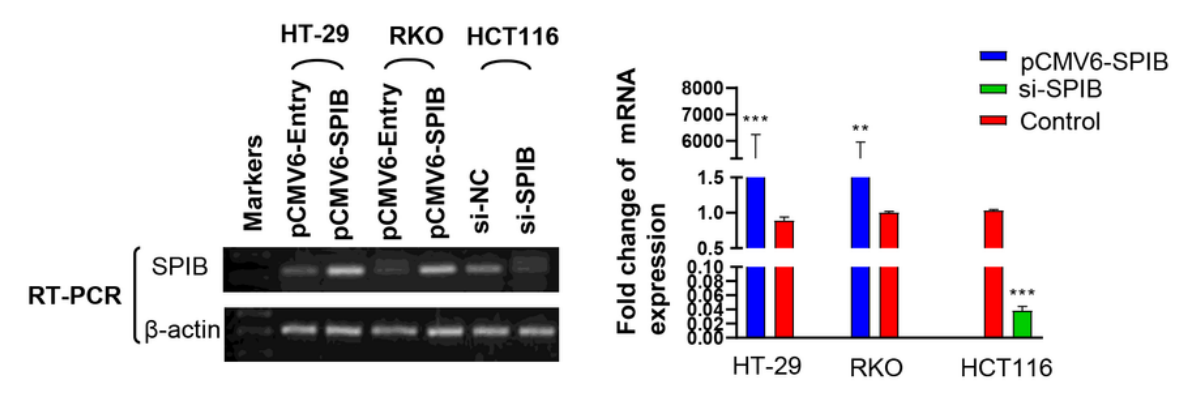

d pCMV6-Entry pCMV6-SPIB

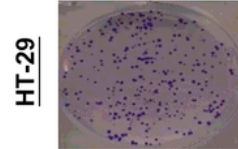

$\frac{\hat{r}}{x}$
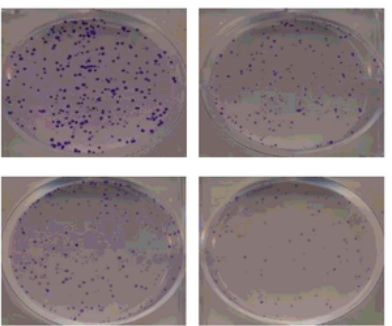

f

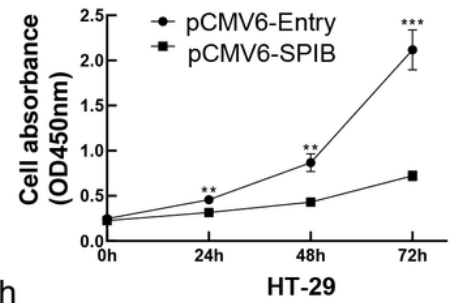

$\mathrm{h}$

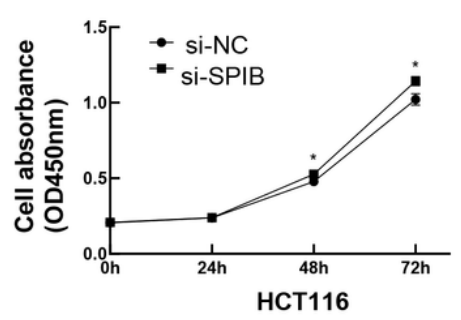

Figure 2

SPIB inhibits the proliferation of CRC cells. The mRNA and protein levels of SPIB in overexpressed and knockdown cell lines were

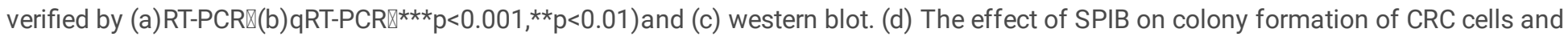
(e)the quantitative analysis of colony formation $(\star \star \star p<0.001)$. ( $f \square \mathrm{g} \square \mathrm{h}$ ) The effect of SPIB on the proliferation of CRC cell lines was detected by CCK-8ॠ*** $\left.<0.001,{ }^{* *} p<0.01,{ }^{\star} p<0.05\right)$. 

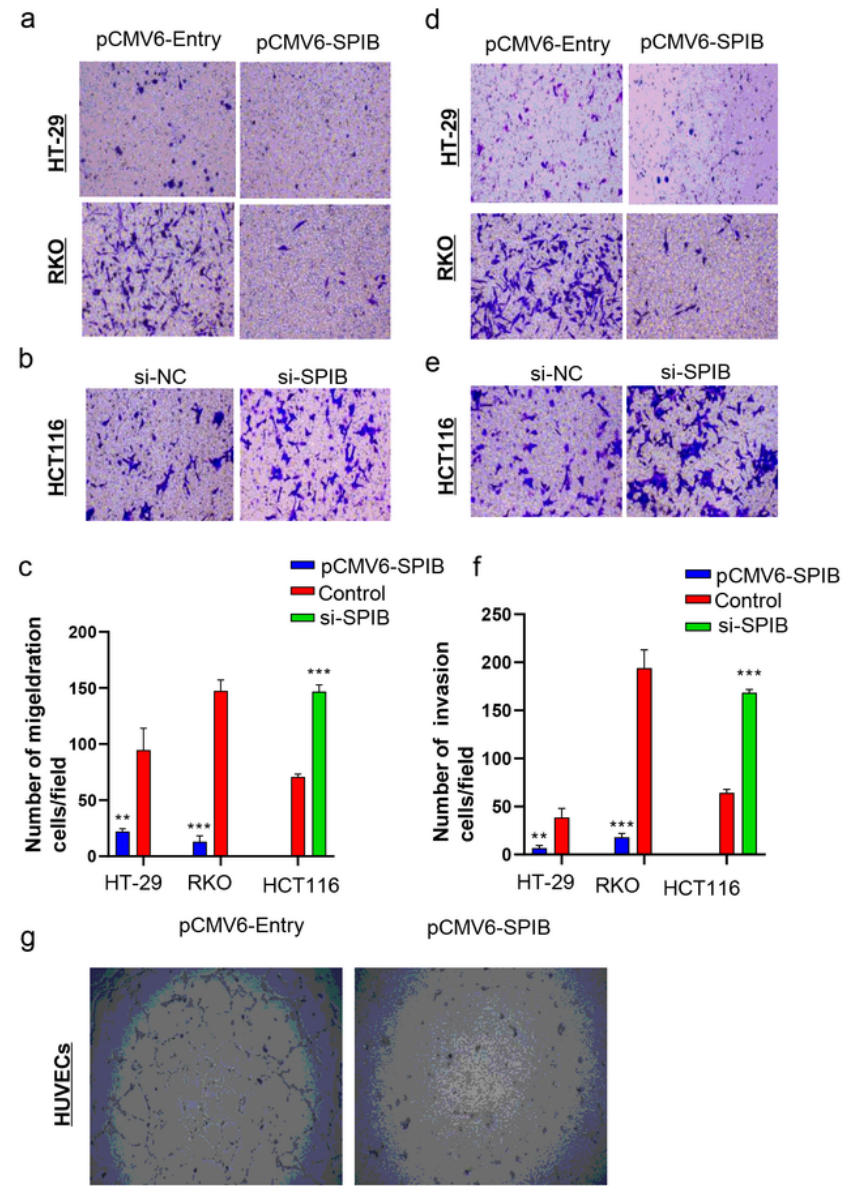

\section{Figure 3}

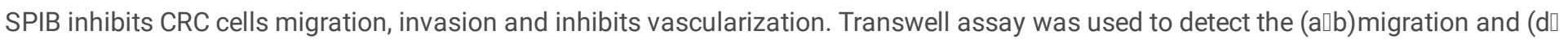
e)invasion capabilities of CRC cells , the number of migration(c) and invasion (f)cells after overexpression and silencing of SPIB was quantitatively analyzed $\left.\square^{\star \star *} p<0.001,{ }^{\star *} \mathrm{p}<0.01\right)$. (g)The tube formation assay was used to detect the ability of SPIB to inhibit tumor vascularization. 

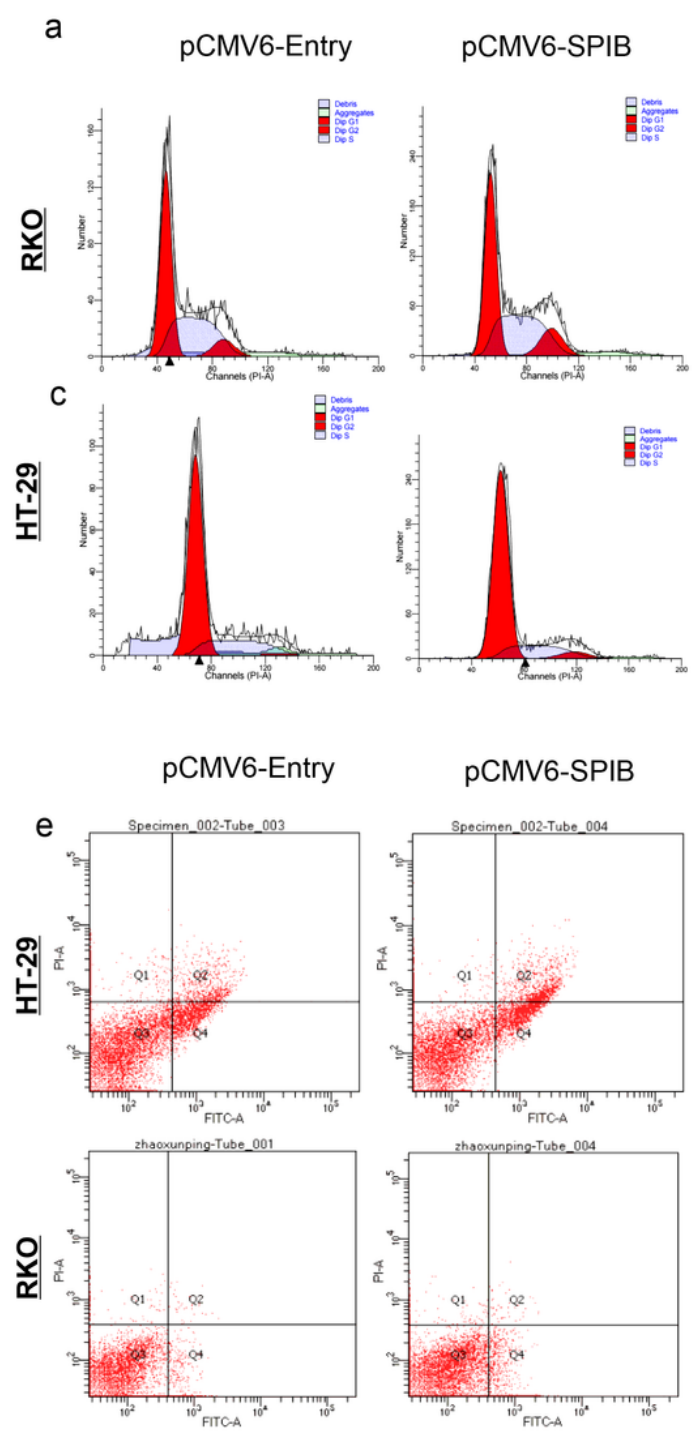

b
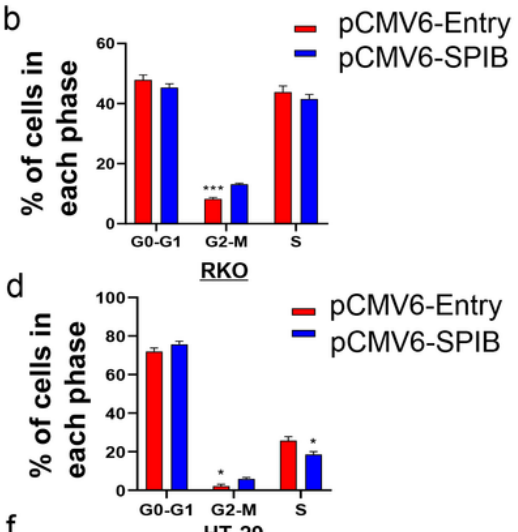

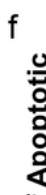

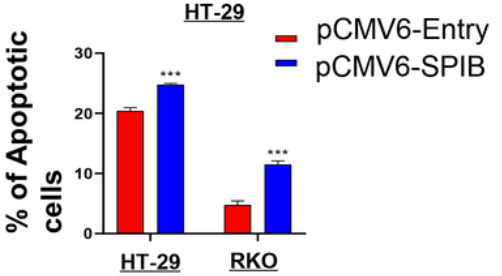

\section{$9 \quad \underline{\text { HT-29 }}$ RKO}

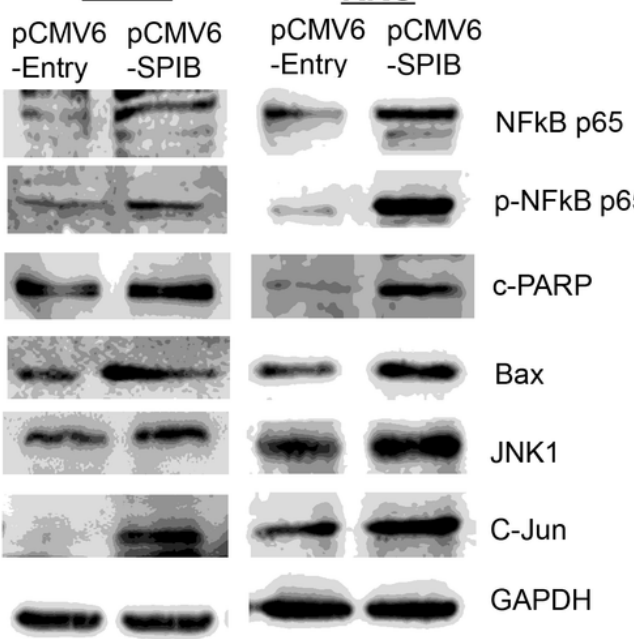

Figure 4

Overexpression of SPIB induced cell apoptosis and cell cycle arrest of CRC cells. SPIB induced the cell cycle of (aロb) RKO and (c $\square$ d)HT-29 cells arrest in G2/M phase. Students' t-test was used to evaluate values ( ${ }^{\star \star \star} p<0.001$, ${ }^{\star} p<0.05$ ). (elf) The effect of SPIB on apoptosis rate of HT-29 and RKO cells was detected by flow cytometry, students' t-test was used to evaluate values $(\star \star \star p<0.001)$.खg) Western blot was used to detect the effects of SPIB on the protein expression level associated with apoptosis in HT-29 and RKO cells, GAPDH as control. 
a

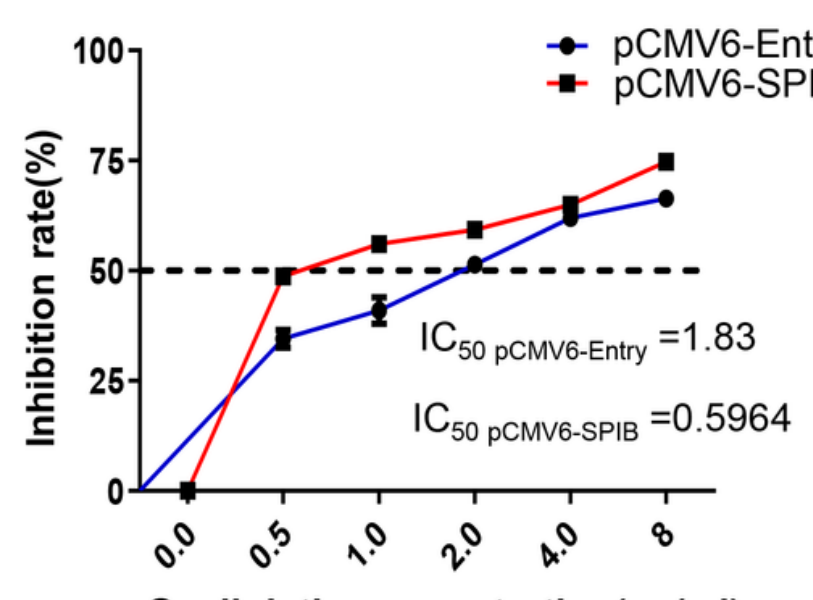

Oxaliplatin concentration(ug/ml)

b

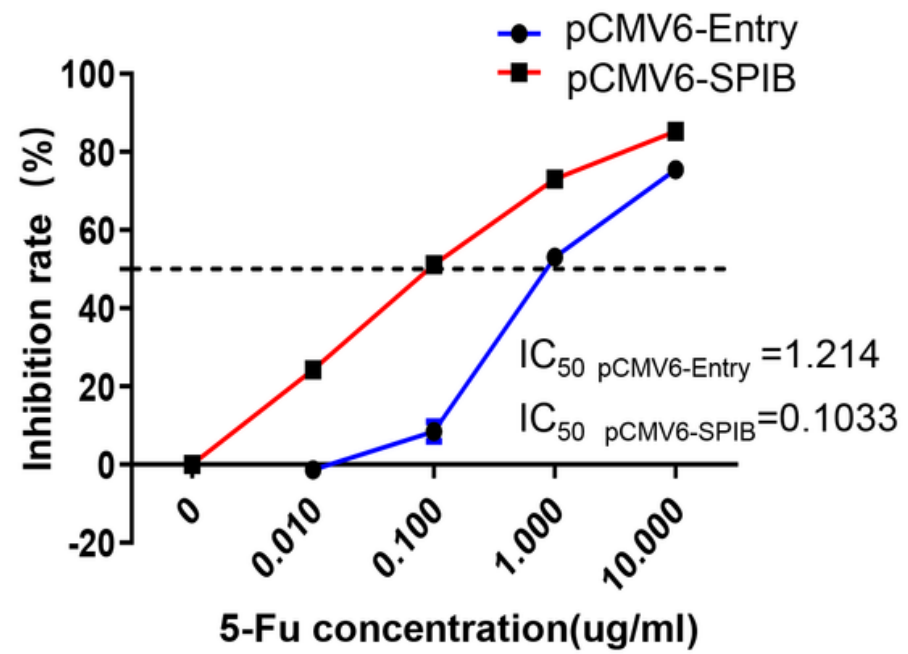

Figure 5

Overexpression of SPIB increased the sensitivity of CRC cells to oxaliplatin and 5-FU. The inhibitory effect of (a)oxaliplatin and (b)5-FU on the growth of RKO cells transfected with pCMV6-Entry or pCMV6-SPIB was detected by CCK-8, the IC50 was calculated by GraphPad software. 
a
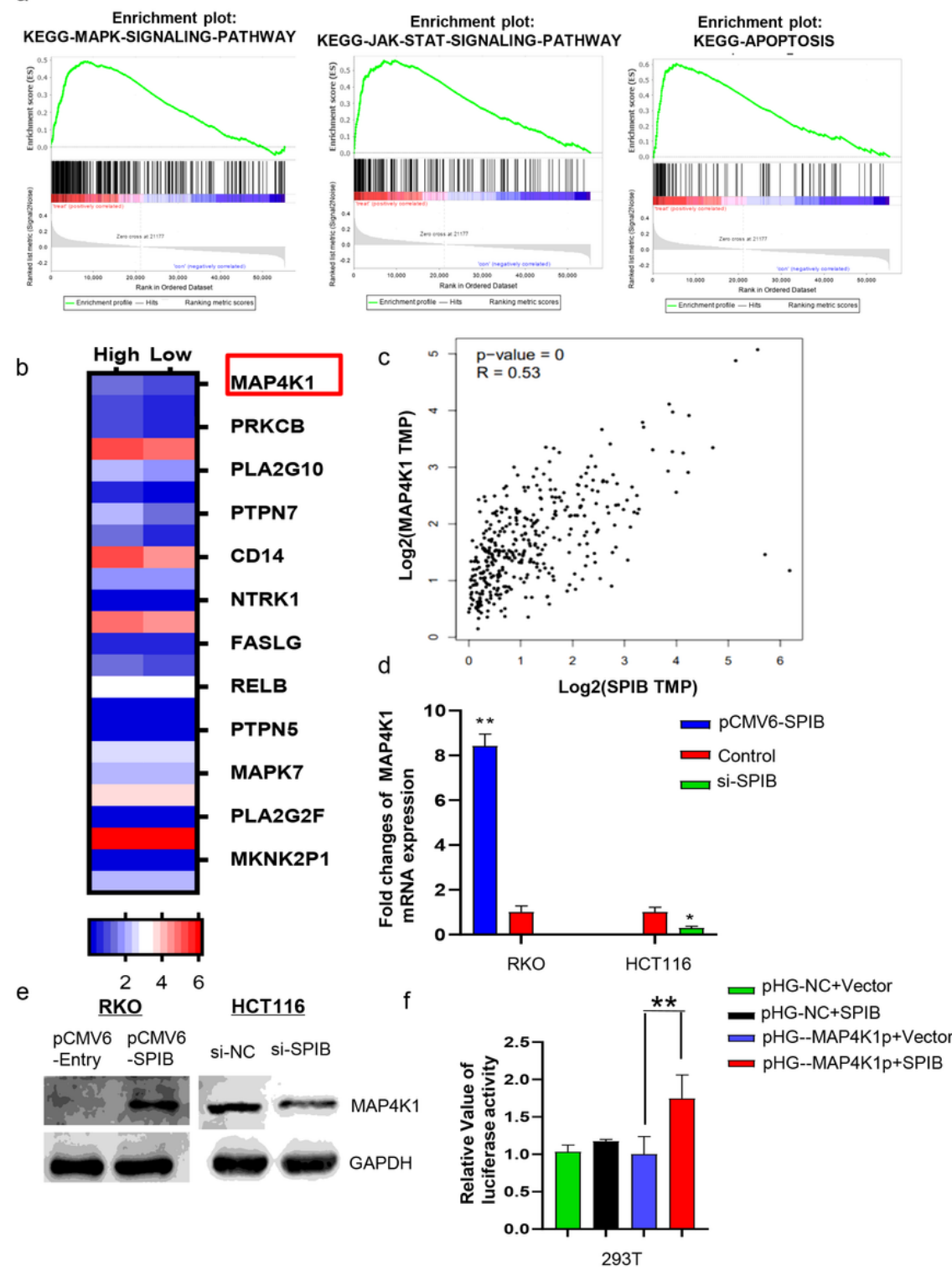

Figure 6

SPIB can activate the promoter of MAP4K1 and enhance the expression of MAP4K1. (a) SPIB-related signaling pathways in CRC were identified by gene set enrichment analysis. (b)The expression of a group of genes related to SPIB expression level in MAPK signal pathway. (c) The correlation between SPIB and MAP4K1 in GEPIA database (http://gepia.cancer-pku.cn/detail. php). (d) QRT-PCR and \e)western blot were used to detect the expression of MAP4K1 after SPIB overexpressing and silencing. (f囚Double luciferase reporter assay was used to detect the interaction between SPIB and MAP4K1 promoter region. 
a

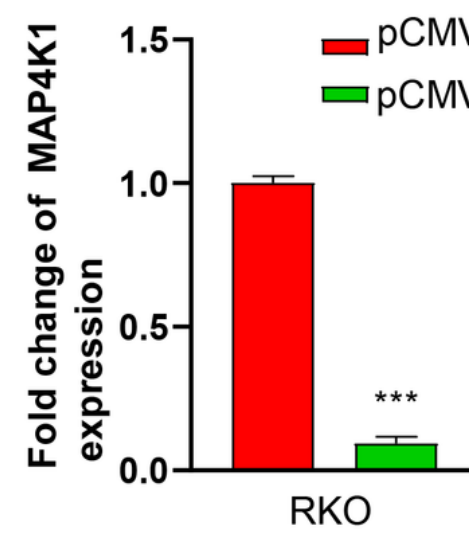

C

$\underline{\text { RKO }}$
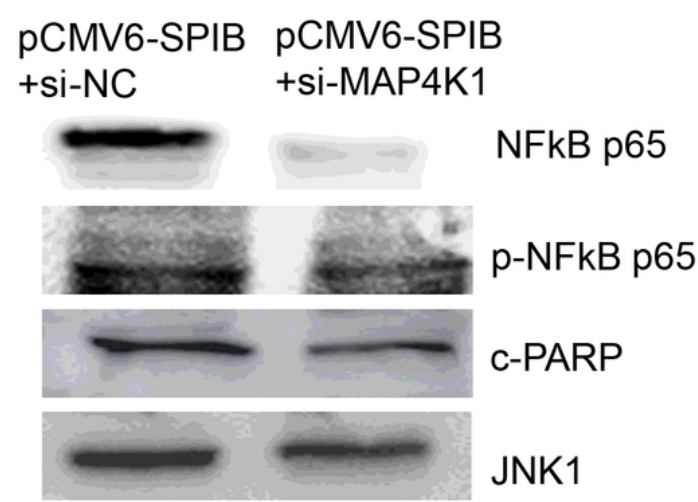

JNK1

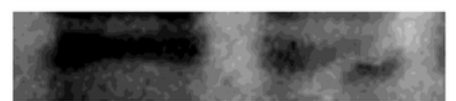

C-Jun
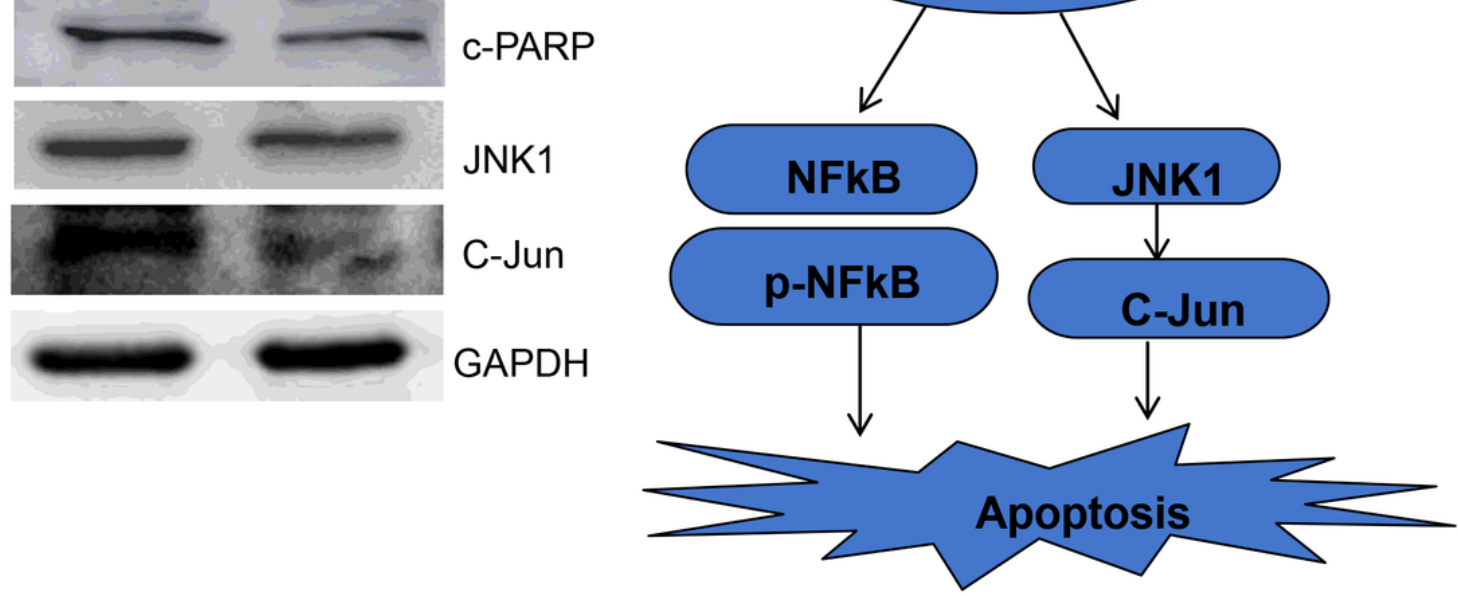

Figure 7

The effect of silencing MAP4K1 in SPIB overexpressed stable cell lines on the expression of apoptosis-related protein. (a)QRT-PCR and (b) western blot confirmed the expression of MAP4K1. (c) Western blot was used to detect the expression of NFkB P65, p-NFkB P65, cPARP, JNK1, C-Jun after silencing MAP4K1, GAPDH as control. (d) Schematic diagram of SPIB promoting apoptosis. 